\title{
Malignant Melanoma in an Albino
}

Spencer E. E. Efem ${ }^{1}$, Maurice E. Asuquo ${ }^{1}$, Godwin Ebughe ${ }^{2}$

\section{Abstract}

Oculocutaneous albinism is a rare autosomal recessive disorder characterised by generalised depigmentation, photophobia, decreased visual acuity, and nystagmus. Malignant melanoma is rare in patients with albinism. We report a case of a large advanced fumigating tumour on the right forearm of a male Nigerian albino diagnosed clinically as squamous cell carcinoma but histological proven to be melanoma.

Keywords: Albinism, malignant melanoma, skin.

\section{Case Report}

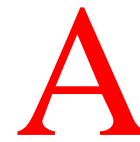

41-year-old male oculocutaneous albino (OCA) was referred with a 6 months history of a large ulcerated tumour on his right forearm to the surgical out patients department of the University of Calabar Teaching Hospital, Calabar, Southern Nigeria. The lesion started as a boil on the right forearm and increased rapidly in size eventually ulcerating. Apart from itching, he denied any history of trauma or injury. He attended a chemist shop where the lesion was excised and dressed daily but when it kept increasing in size rather than healing, he was referred to the University of Calabar Teaching Hospital.

He had not been hospitalised before this visit and no known drug allergy. He is one of five siblings in a polygamous family but he is the only albino in the family. He is married to a non-albino and their three children are not albinos.

On examination he was found to be an otherwise well looking OCA with numerous Hutchison's freckles on the face and forearms that are constantly exposed to sunlight. He had a large fungating ulcer cancer on the right forearm near to the antecubital fossa (Figure 1). The lesion bled as the dressings were removed to expose it for inspection.

University Departments of Surgery ${ }^{1}$ and Pathology ${ }^{2}$, University Teaching Hospital Calabar, Nigeria.

Correspondence to Dr M. E. Asuquo, GPO Box 1891, Calabar, Nigeria.

Email: mauefas@yahoo.com

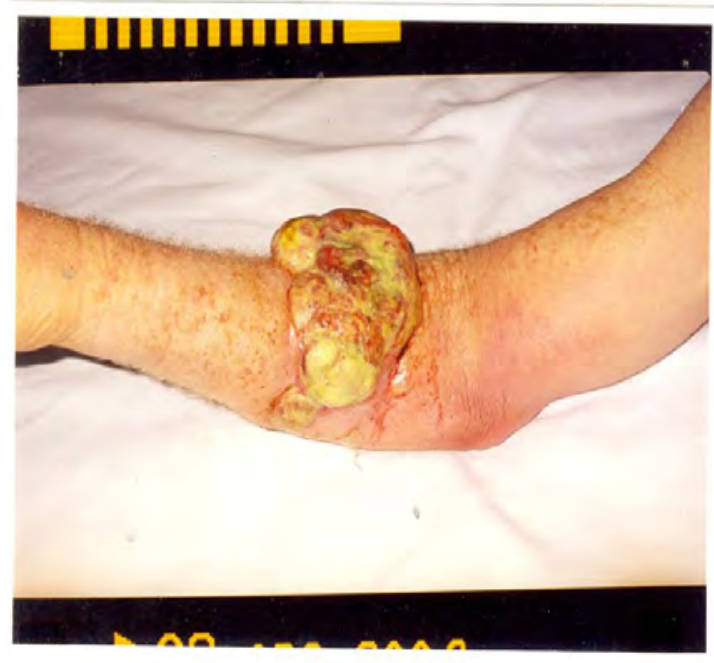

Figure 1 - Malignant ulcer/ melanoma

The tumour had lobes and nodules while the surrounding skin had red-pigmented deposits presumably satellite and in-transit lesions. The ipsilateral axillary nodes were not palpably enlarged.

Apart from a blood pressure of 140/90 mmHg he had no systemic disturbance. A clinical impression of squamous cell carcinoma was made. The tumour was widely excised and sent for histology, which revealed a tumour composed of large epitheloid to oval cells in pseudo glandular pattern and extends from epidermis to deep subcutis with no pigmentation observed, amelanotic melanoma (Figure 2). The patient received a course of methotrexate $100 \mathrm{mg}$ thrice weekly after discharge. 
After three courses of methotrexate, he defaulted only to resurface after a year with more advanced recurrent disease. After readmission, he left the hospital against medical advice.

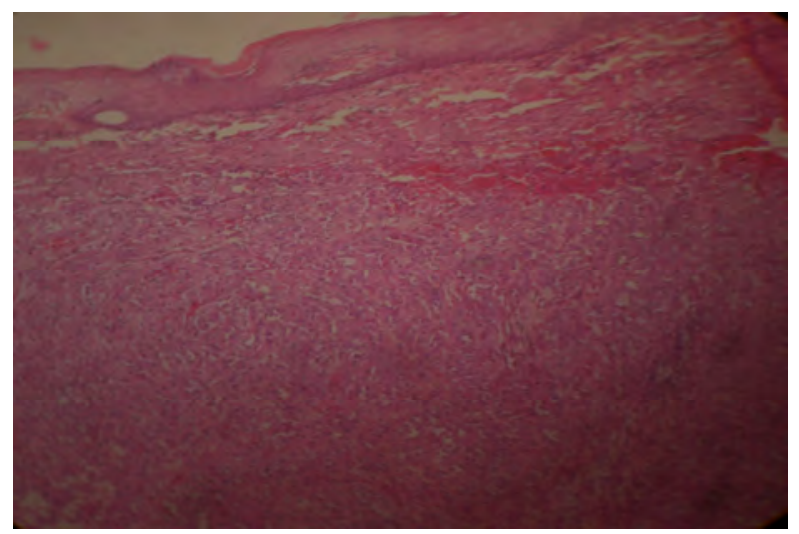

Figure 2 - Amelanotic melanoma

\section{Discussion}

Albinism occurs because of inborn error of metabolism in which there is deficiency of the enzyme tyrosinase responsible for both the hydroxylation L-tyrosine to 34 dihydrophenylalanine (DOPA) and its subsequent oxidation to dopaquinone. Nonenzymatic reactions in polymerisation of dopaquinone derivatives and reaction with a specialised protein to form melanoprotein in melanocytes ${ }^{1}$. Melanocytes are present in albinos but they do not contain melanin. Albinism is a genetically inherited autosomal recessive (A-R) condition. Two major formsOCA1 (Tyrosinase gene), OCA2 associated with alterations of the $\mathrm{P}$ gene on chromosome 15. Oculocutaneous 2 is twice as common as OCA 1 in African and African-American populations $^{3}$. Oculocutaneous 2 presents as 2 phenotypes depending on the presence or absence of pigmented patches or ephelides or dendritic freckles on exposed areas of the skin $^{4}$. Melanin acts as a sunscreen protecting the skin from damaging effect of ultraviolet radiation increasing the risks of skin cancers such as SCC, basal cell carcinoma (BCC) and malignant melanoma (MM). Globally the prevalence of melanoma in albinism remains relatively rare with about 30 documented cases in literature ${ }^{2}$. In a review of malignancies in albinos no case of MM was found by Yakubu and Mabogunje ${ }^{5}$ in Zaria, Northern Nigeria, Datubo-Brown in Port Harcourt, Southern Nigeria ${ }^{6}$, Kromberg et al in South Africa ${ }^{4}$ and George et al Ibadan South West Nigeria ${ }^{2}$. A review of medical literature failed to reveal any case of MM in albinos in Nigeria ${ }^{2}$. However, Luande et al in Dar-es-Salam, Tanzania reported 33 cases of skin cancer; SCC-29, BCC-3 and a case of $\mathrm{MM}^{7}$.

This is the first case of MM in an albino of Negroid ancestry in our centre. There have however been sporadic descriptions of MM in curious sites such as metastatic MM of the nasal cavity, choroidal malignant melanoma ${ }^{8}$ and primary malignant melanoma in the lungs 9 all occurring in OCA's of Caucasian ancestry.

Our patient came to us with advanced and incurable disease because he went to a chemist shop for treatment in the early stage of the disease when biopsy and early diagnosis would have been established to enable curative surgical excision. Skin lesions in albinos should not be taken lightly but should always be biopsied and early diagnosis established.

\section{References}

1. Sodeman WA: Inherited diseases caused by deficiency of product. Metabolic Biochemistry in Pathologic Physiology Mechanisms of Disease. Saunders 1979: p. 91.

2. George AD, Ogunbiyi AD, Daramola OOM, Campbell OB. Albinism among Nigerians with malignant melanoma. Tropical Doc 2005; 35: 55-56.

3. Durham-Pierre D, Gardner JM, Nakatsu Y, King RA, Francke U, Ching A, Aquaron R, del Marmol $\mathrm{V}$, Brilliant $\mathrm{MH}$. African origin of an intragenic deletion of the human $\mathrm{P}$ gene in tyrosinase positive oculocutaneous albinism. Nat Genet 1994; 7(2): 176-179.

4. Kromberg JG, Castle D, Zwane EM, Jenkins T. Albinism and skin cancer in Southern Africa. Clin Genet 1989; 36(1): 43-52.

5. Yakubu A, Mabogunje OA. Skin cancer in African albinos. Acta Oncol 1993; 32(6): 621-622. 
6. Datubo Brown DD. Primary malignant skin tumours in Nigerians. J Natl Med Assoc 1991; 83(4): 345-348.

7. Luande J, Henschke CI. Mohammed N. The Tanzania human albino skin. Natural history. Cancer 1985; 55(8): 1823-1828.
8. Casswell AG, Mc Cartney AC, Hungerford JL. Choroidal malignant melanoma in an albino. $\mathrm{Br} \mathrm{J}$ Ophal 1998.

9. Özdemir N, Cangir AK, Kutlat H, Yavuzer ST. Primary malignant melanoma of the lung in oculocutaneous albino patient. Eur J Cardiothorac Surg 2001;20(4):864-7. 